Izvorni naučni članak

UDK: 616.981.45(450.341)"13/17"; 614.2(450.341)"13/17"

ID: 202539020

Marija Kocić

Naučni saradnik, Odeljenje za istoriju

Filozofski fakultet, Univerzitet u Beogradu

Čika Ljubina 18 - 20, 11000 Beograd, Srbija

marijakocich@gmail.com

\title{
RAZVOJ ZDRAVSTVENE SLUŽBE U VENECIJI (MAGISTRATO ALLA SANITA')*
}

Apstrakt: Ovaj rad prati razvoj sanitarnih službi u Veneciji, od trenutka kada se za njima javila potreba u razvijenom obliku, i koje su bile u funkciji da kraja nezavisnosti Venecije. Venecija je doživela svoj najveći uspon tokom ovog perioda zahvaljujući trgovini sa Levantom. Međutim, kao što je istorija pokazala, to je imalo i negativne strane. Jedna od njih je bila kuga, koja je kosila stanovništvo Evrope u više navrata, pri čemu nikoga nije štedela, pa ni Veneciju.

Ključne reči: kuga, lazaret, Crna Smrt

Ne MeSH: Venecija, Magistrato alla Sanità

Key words: plague, lazaret, Black Death

Non MeSH: Venice, Magistrato alla Sanità

* Ovaj rad nastao je u okviru projekta „Modernizacija Zapadnog Balkana“ Ministarstva prosvete, nauke i tehnološkog razvoja Republike Srbije (ev. br. 177009). 
Početkom drugog milenijuma Venecija je počela da razvija trgovinu sa istočnim Mediteranom, zahvaljujući olakšicama koje je dobila od slabih vladara Vizantije. U ovom periodu uspostavljeni kontakti tokom narednih vekova dalje su unapređivani. S druge strane, obično stanovništvo kratkog životnog veka bilo je okrenuto lokalnoj sredini u kojoj je tražilo leka za sve svoje bolesti, u doba kada je način lečenja gravitirao je između nalaženja utehe u natprirodnom i pučkog sujeverja.

Prekretnicu u istoriji Evrope predstavlja velika epidmija kuge poznata kao Crna Smrt, po svom karakteru vrsta bubonske kuge. Na tlu Evrope kuga se prvo pojavila u Mesini na Siciliji oktobra 1347, zbog čega pojedini istoričari pretpostavljaju da je ona došla sa Istoka. Kugu izaziva bacil Yersina pestis. Ova bakterija duguljastog je oblika i egzistira u stomaku insekta Xenopsilla cheopsis (koga prenose pacovi). Jedna Yersina pestis može se razmnožiti na hiljade jedinica za samo sat vremena. Bibliografija radova koji se odnose na Crnu Smrt i kugu u ranomodernoj Evropi posebno onih koji su publikovani u Italiji, objavljena je u: Testi poseduti dalla biblioteca Scienze della Storia e della documentazione storica la Peste del 1348. [1] Po teritorijalnom obimu gde se epidemija proširila ona predstavlja jedinstveni slučaj u istoriji predmoderne Evrope. Kuga je za samo nekoliko godina (1347-1351) koliko je trajala ova epidemija, odnela trećinu stanovništva Starog Kontinenta. [2, 3 pp300310] Od toga vremena ona postaje endemična pojava u svim delovima Evrope tokom naredna tri stoleća. Iako postoje nedoumice zbog čega se Crna Smrt pokazala ovako razornom, ona je po obično stanovništvo i sve vladajuće hijerarhije imala katastrofalne posledice. Jednačeći je sa Božijom kaznom koja se sručila na hrišćane zbog njihovih grehova, katolička crkva osim elegičnog patosa u njenoj deskripciji, nije mogla da ponudi drugi način za saniranje njenih posledica.

Venecija je Crnu Smrt iskusila na vrlo bolan način. Veliki deo njenih podanika postao je žrtva epidemije, sa kojom njene vlasti (na tadašnjem nivou) nisu umele da se izbore. Tek nakon što je kuga odnela značajan broj žrtava Veliko Veće izabralo je 1348. tri člana, koji su dobili ovlašćenje da prate koliko ljudi dnevno umire u pojedinim delovima grada i organizuju njihovu sahranu. Propisi doneti te godine ostali su na snazi tokom prve polovine XV veka. [4 pp753] Nakon što se Crna Smrt povukla interesovanje vlasti za sanitarne mere odjednom je splasnulo.

Početkom treće decenije XV veka Venecija je pokušala da proširi svoju teritoriju na istočnoj jadranskoj obali. Pod udarac njenog oružja dospeli su Bar, Ulcinj i Skadar. Ovo je izazvalo strah da kuga koja se pojavila u tim oblastima ne bude preneta na 
teritoriju Venecije. Ovo se razaznaje iz pisanja Marina Sanuda, koji prepričava odluku iz 1423, donetu upravo ovim povodom. Senat je rešio da sagradi karantin na mestu gde se nalazila crkva sv. Marije od Nazareta. Pošto je ovo mesto pripadalo monasima sv. Augustina, predviđeno je da im bude ustupljena zemlja u delu grada poznatom kao San Chimento. Majstor Gabrijel ovlašćen je za izgradnju lazareta i organizaciju njegovog osoblja, koje je trebalo da broji četiri služitelja za obolele muškarce i isto toliko za nadgledanje obolelih žena. Lazaret je trebalo da ima priora i kapelana sa platom od 40 dukata godišnje, dok su ukupni troškovi njegovog izdržavanja padali na teret Officio del sal. Deo Marina Sanuda koji se odnosi na osnivanje prvog lazareta $\mathrm{u}$ Veneciji navodimo u originalu, jer se jezik kojim se on izražava, u određenoj meri razlikuje od današnjeg italijanskog: Per la peste che scomenzò in questa Terra fo preso in Pregadi [or per Nazaretto, dove debe star amorbodi, il luogo di Sanata Maria di Nazaret, qual erra d' iflr]atti di Santo Augustin della Caritade, et foli datto per cambio il luogo di San Cimento et questo fo fatto per mezo di maistro Cabriel de l'ordine delli Eremitani et fo preso di fabricar detto locho per li amorbatti dove li fosse dà il viver e medegadi e fatto uno prior con quatro serventi per li homeni et 4 per le femene e uno capellan con ducati 40 a l'anno et le spesse, et si paga la dita spesa per l' Officio del Sal. [5; I p22]

Kada se pojavila nova opasnost od kuge Senat je 17. oktobra 1440. ponovo imenovao trojicu plemića „da ispitaju i prouče uzroke koji dovode do kvarenja vazduha”. [2] Prema odluci donetoj 1464. trebalo je da se "naš Gospod i zaštitnik Isus Hrist" moli za milost. Od patrijarha je traženo da na prve znake kuge naredi čitanje molitvi u svim crkvama i manastirima u gradu, da bi se odvratila opasnost od opake bolesti. Apelovanje na verski sentiment logično je u uslovima kada je katolička crkva još uvek imala najviše uticaja na formiranje stava prema svemu što je okruživalo čoveka, pa i prema bolesti. Tom prilikom Senat da imenovao dvojicu građana (popolani) u svakoj gradskoj četvrti (sestiere). Svako od njih dobijao je platu, najviše $4 \mathrm{du}-$ kata mesečno iz Ufficio del Sal. Oni su zaduženi da redovno obilaze poverene im četvrti i da svakog za koga posumnjaju da je oboleo od kuge odmah smeste u lazaret, „na način koji odgovara njihovom društvenom statusu“. Njihov prevoz morao je biti završen u najkraćem roku. U tu svrhu stajala su im na raspolaganju dva broda iznajmljena od Provveditore al Sali. Pored njih, druga dva broda stajala su usidrena u delu grada pozatom kao Nova Zemlja (Terra Nova) i dva na Rijaltu. Izabrani popolani trebali su da vode računa o tome da kuće onih za koje se utvrde da su oboleli od kuge budu propisno evakuisane. Po nalogu Senata oni su bili dužni da ubede njihove stanare da napuste grad. Pri svemu tome oni su imali prava da im ponude i određenu sumu novca, da bi ih privoleli na takvu odluku. U obavljanju dužnosti 
oni su mogli da se konsultuju sa don Fulgencijem, koji se dobrovoljno ponudio da posećuje zaražene osobe. [6] Navedena mera predstavljala je u datim okolnostima praktično rešenje u sistemu, koji još uvek nije posedovao instituciju zaduženu za zaštitu javnog zdravlja.

Ustanova poznata kao Nazaret pokazala se od velike pomoći u odbrani grada od širenja zaraze. Međutim, ona nije mogla biti potpuno efikasna zbog toga što su se mnogi koji su napustili lazaret nakon što su bili izlečeni vraćali u grad, prenoseći zarazu osobama s kojima su dolazili u kontakt. Provveditore al Sali dobio je 1468. ovlašćenje da sagradi novi karantin (locum) na mestu Vigna Murata. Svi oni koji napuste lazaret nakon što se izleče morali su preći u karantin i tamo provesti 40 dana. Tek nakon toga mogli su se vratiti u grad. Kako je mesto Vinja Murata pripadalo monasima sv. Đorđa predviđeno je da im Provveditore al Sali isplaćuje 50 dukata mesečno na ime rente. Senat je ove providure ovlastio punom odgovornošću za sve troškove, koji budu nastali u toku izgradnje ovog karantina. [6]

Kontakti sa Osmanskim carstvom koji su tokom XV veka postali češći, i trgovina sa Levantom i severnoafičkom obalom (koje su važile za izvorišta kuge), nagonili su vlasti u Veneciji da budno motre na zdravstveno stanje, u prvom redu mornara i stranaca. Vlastima je postalo jasno da su mesta u gradu koja su naseljavali mornari bila prva zahvaćena kugom. [4 pp753] U razdoblju od 1456. do 1528. kuga je 14 puta pogodila Veneciju. [6] Posebno se po njeno stanovništvo pokazala opasna epidemija iz 1478. Kuga iz 1479. ne pominje se u analima koji tretiraju ovaj period zbog čega se može pretpostaviti da ona nije imala po stanovništvo Venecije razorne posledice.[7 pp245-249] Veliki broj žrtava koje je kuga tom prilikom odnela otkrile su Senatu potrebu da izdvoji posebnu Magistraturu, kojoj bi bio poveren nadzor nad zdravljem stanovnika u slučaju epidemije. [4 pp753] Ovo predstavlja preloman momenat $\mathrm{u}$ istoriji Venecije, kada se po prvi put javila potreba za formiranjem posebnog tela, koje je kasnije postalo nosilac njene zdravstvene kulture. Senat je 1485. izglasao dekret, koji je predviđao imenovanje trojice plemića sa zvanjem sopra la Sanità della Terra. Oni su imenovani na godinu dana, nakon čega su druga trojica plemića preuzimala njihova ovlašćenja. [4 pp754] Kako ga je Vetor Sandi u XVIII veku razumeo taj propis on nije značio da su pomenuti službenici delovali u okviru posebnog Magistrata, već su ostali u okviru Ufficio al Sali. Za svoj rad dobijali su platu upravo iz ovog Magistrata. [4 pp754] Savremeni istoričari smatraju da je najkasnije do 1490. došlo do izdvajanja zdravstvenog ureda u Veneciji. [6] Karlo Ćipola smatra da je na osnovu odluke Senata od 7. januara 1486. bio ustanovljen 
Zdravstveni Magistrat (Magistrato alla Sanità). Pomenuta odluka predviđala je da se svake godine biraju tri plemića sa zvanjem Provveditori al Sanità. Oni koji su tom prilikom nominovani od strane Senata, nisu smeli da odbiju ovu službu. [2]

Ono što je posebno plašilo mletačke vlasti u vreme epidemije kuge bila je raspojasanost i kriminalno ponašanje, u porastu posebno kod nižih slojeva gradskog stanovništva, koje je bilo najbrojnije. Strah od smrti budio je u ljudima sentimente nesvojstvene običnim okolnostima. Spoznaja da sutrašnji dan možda neće dočekati uticalo je da mnoge potencijalne žrtve pomora počnu da namiruju svoje u normalnim okolnostima neprimerene sklonosti. Raspusničko ponašanje koje je nekontrolisanu seksualnost koristilo kao ventil u emocionalnoj samoodbrani od suočavanja sa smrću, uticao je na pad javnog morala. Međutim, ono što je posebno brinulo vlasti predstavljala je činjenica da su se upravo u vreme epidemije dešavali teški zločini, rastao broj krivičnih dela, i u krajnju ruku, postojala potencijalna opasnost od pobune.

Sa razvojem zdravstvene službe u Veneciji pod državnu regulativu dospele su i obaveze medikusa, na koje se odnosi odluka Senata iz 1514. Kada je Magistrat za zdravstvo obavešten o sumnji da je neka osoba obolela od kuge on je u roku od nekoliko sati, najviše dana, morao da pošalje medikusa da pregleda bolesnika i utvrdi da li se radi o kugi. Pored toga i da li na telu obolelog postoje „apostema, carbon over altro segno", karakteristični za ovu bolest. Ukoliko bude potvrđeno da se radilo o kugi mesto je moralo odmah biti stavljeno pod karantin, zajedno sa svim stanovnicima i onima koji su dolazili u kontakt sa zaraženom osobom. Zatim su na lice mesta izlazili notar i pomoćnik Magistrata da bi pod zakletvom ispitali stanovnike. Prvi je bio ispitivan vlasnik kuće, potom i ostali kako bi se utvrdilo odakle je poticala bolest. Ovaj zakon je od značaja jer je utvrdio ponašanje medikusa, koji je bio u obavezi da obolelima i onim osobama sa kojima su oni bili u kontaktu pruži neophodnu zdravstvenu negu. Medikus je po ovom zakonu morao da odleži u karantinu 22 dana, bez obzira da li je bio u fizičkom kontaktu sa obolelim ili je stajao ispred vrata i samo ispitivao njegov urin. [6]

Tokom XVI veka u nekoliko navrata $(1504,1537,1553,1582)$ preuzimane su mere koje su upotpunile njen rad. Njima je bila određena organizacija i obaveze svakog podanika na poštovanju donetih mera, posebno u vreme epidemije. [4 pp755-756] U ovom veku velika epidemija pogodila je 1576. Veneciju, čijim se istraživanjem bavio Paolo Preto. [8] Kuga ovog puta nije ostala ograničena samo na teritoriju 
Venecije, već je zahvatila veliki deo Apeninskog poluostrva. Prema zaključcima pojedinih istoričara u ovom dobu epidemija kuge nije bila toliko česta, ali je zato imala ubojitije dejstvo. Tokom epidemije 1576. u gradu je umrlo 25\% od ukupnog broj stanovnika. [6]

Do kraja XVI veka Venecija je posedovala dobro organizovanu zdravstvenu službu, čiji je obrazac funkcionisanja pokušala nametnuti i svojim kolonijama. Svi gradovi i trgovačka uporišta, posebno ona koja su imala razvijenu trgovinu sa Levantom, morala su da poštuju odredbe Zdravstvenog Magistrata, u prvom redu one koje su se odnosile na karantin. Kada je Fajns Morison iz Alepa, gde se zadržao nekoliko dana, hteo da otputuje za Kandiju, koja je tada bila sastavni deo Mletačke Republike, on je morao da izdrži karantin (kako ga navodi u itineraru Quarantana). U Alepu je u to vreme (1596) rezidirao mletački konzul, koji je bio u obavezi da izda dokumenat Morisonu, jer je on odavde odlazio na deo mletačke teritorije. Ovo je poslužilo kao odličan povod Fajnsu Morisonu da se upozna sa propisima, koje je mletačka vlast u ovo vreme naširoko primenjivala. Putnici koji su iz Alepa odlazili u Italiju morali su sa sobom da ponesu i zdravstvenu potvrdu (Testimonie of Health) zvanu Boletino pre nego pođu ili se vrate. Kako je ovaj putnik primetio Venecija je bila mnogo rigoroznija u tim stvarima, nego ostale italijanske države. Kao glavni razlog toga Morison navodi njenu trgovinu sa Carigradom, u kome je kuga neprestano bila prisutna. [9; II pp75] Nasuprot Veneciji Osmansko carstvo kasnilo je sa izgradnjom sanitarnog sistema, ali je i ono od XVII veka počelo intenzivnije da primenjuje sistem karantina. [10] Međutim, na sve evropske države u organizaciji zdravstvene službe, pre svega, karantina imala je najveći uticaj Venecija i druge italijanske države, koje su prve počele da primenjuju ovaj vid zaštite. [11]

Između 1613. i 1666. Evropa je bila opustošena serijom epidemijâ kuge. Prema skorijim istraživanjima epidemije koje se javljaju u razdoblju od 1613. do 1635. pripadaju ciklusu koji je određen kao “indijski”. Time je ukazano da je glavno polazište bacila koji je pet decenija u ciklusima odnosio stanovnike Starog Kontinenta, bila Indija (1611). Drugi ciklus koji otpočinje već 1636. i traje do 1666. određen je kao „levantski”, pri čemu je za njeno izvorište ubiciran Carigrad. Ono što je posebno pogodovalo da kuga punih pet decenija pustoši Evropu predstavlja činjenica da se ona od 1618. do 1659. nalazila u konstantnom ratu. [12] Kao posledica latentne opasnosti od pojave kuge i, s druge strane, razvoja međunarodnog prava, koje se u razmiricama Tridesetogodišnjeg rata (1618-1648) uobličavalo, došlo je do sklapanja prvog međudržavnog sporazuma, koji se odnosi na zdravstvenu zaštitu u slučaju 
kuge. Sporazum je zaključen 5. septembra 1652. između Velikog toskanskog vojvodstva i Republike Đenove, dok su njegove odredbe predviđale zajedničko delovanje njihovih zdravstvenih službi na saniranju posledica kuge. [13]

Za jednu od najvećih epidemija kuge koja je pogodila Apeninsko poluostrvo tokom XVII veka odgovorna je bila nemačka vojska, koja je septembra 1629. upala u severnu Italiju. Navedeni stav potiče od Alesandra Tadina, fizika i jedno vreme prvog čoveka zdravstvene službe u Milanskom vojvodstvu. O nemačkim vojnicima koji su se ulogorili kod jezera Komo Tadino piše: questa gente Alemana per il più del tempo contaminata di peste, per la mala regola del vivere, E' anche per esser molto sporca in ogni cosa. [14 p13] Tadino aludira na činjenicu da su nemački vojnici već bili zaraženi kugom pre nego što su upali u Italiju, a kao glavni povod tome ističe nehigijenu i njihov loš način života. Batista Nani prihvatio je ovaj stav. [15; I p495, 16] Početkom 1630. za novog mletačkog dužda izabran je Nikolo Kontarini, u vreme dok je Venecija bila zauzeta odbranom Mantove. U to vreme kuga je uveliko kosila sukobljene vojske, zbog koje je španski general Spinola ostao bez velikog broja vojnika. Marija, sestra španskog kralja, koja je obećana za nevestu Ferdinandu, kralju Ugarske i sinu habsburškog cara, iz Španije je doputovala s velikom pratnjom u Napulj. Ovde je odlučeno da putovanje nastave morem od Trsta a odatle u Beč, jer je kuga uveliko pustošila teritoriju od Đenove do Milana. I Francuska vojska koja je ratovala u severnoj Italiji postala je žrtva ove epidemije. [17 pp322,338-339, 15, $18]$

Zaplašeni smrću koja je lebdela nad njima, stanovnici Venecije po ko zna koji put potražili su spas u molitvama. Senat je sudeći na osnovu tadašnjih istorija apelovao na ljudsku svest da ostane pribrana, delujući na podanike putem njihovog verskog sentimenta. Priređivane su veličanstvene verske procesije u kojima su uzeli učešće najugledniji ljudi države. S odobrenjem pape kanonizovan je nekadašnji mletački patrijarh Lorenco Đustinijani. Navodimo reči iz Nanijevog dela: But in the State of the Venetians, and in the City, the malignant influence exceeded the remedies, till the Senate vowing a magnificient Temple, under the protection of our Lady of health, sending a rich Lamp of Gold to Loretto, a resolving to sollicite with the Pope the canonization of the blessed Lorenco Justiniani, Patrician and Patriarch of the City, besides publick and private Prayers, with Alms and Fasting, God being pacified, the scourage ceased. Whereupon towards the end of the year, the City was with great solemnity published free from Contagion, but the scars remained for a long time. [17 p350] Tokom epidemije 16291632 od kuge stradalo prema pojedinim računicama 30\% mletačkih podanika. [6] 
Po istoričaru, gotovo savremeniku tih dešavanja, Batisti Naniju tokom te epidemije kuga je odnela 60.000 ljudi u gradu i 500.000 u Terafermi. [17 p350]

\author{
R.A G V A G L I O \\ D E L L' O R I G I N E \\ ET GIORNALI SVCCESSI \\ DELLA GRAN PESTE \\ Contagiofa, Venefica, \& Malefica feguita nella Città \\ di Milano, \& fuo Ducato dall Anno 1629. \\ fino all' Anno 1632 . \\ Con le loro fucceflewe Pronifioni, of ordini. \\ Aggiontoui vn breue Compendio delle più fegnalate fpecie di Pefte
in diuerfi tempi occorfe \\ in diuerfi tempi occorfe \\ Dalla Creatione del Mondo fino alla nafcita del signore. \\ Et da $\mathrm{N}$. S. Jimo alli prejenti tempi. \\ CON DIVERSI ANTIDOTI. \\ Defcritti da ALESSANDRO TA DINO Medico Fífico \\ Collegiato, \& de' Conferuarori dell' Illuftrifs. Tribunale

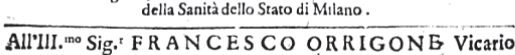 \\ di Prouifione della Città, \& Ducato di Milano.

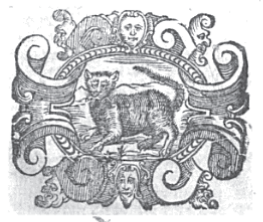 \\ IN MILANO; M:DC.IIL \\ Per Filippo Ghifolfi Ad inftanza di Gio. Battifta Bidel \\ Con: licenzat de'. Superiori, er 'Privilegio.
}

Slika 1 Naslovna strana knjige Alesandra Tadina objavljena u Milanu 1648.

Jedan od značajnih opisa lazareta (karantina) u Veneciji sredinom XVII veka potiče od don Martinucija, koji je priredio knjigu Frančeska Sansovina Venecija Najplemenitiji Grad. Martinucijev doprinos ovom delu je nesumnjiv, jer je on u formi dopuna (adittiones) zabeležio promene u urbanoj strukturi Venecije, koje su se desile tokom prve polovine XVII veka. Prema ovom delu oba lazareta Stari i Novi nalazili su se u gradskoj četvrti Santa Croce. Za Stari lazaret (Lazaretto Vecchio) Sansovino je zabeležio kako je crkva sv. Lazara u prvo vreme služila za lečenje leproznih lica. Oba lazareta, sudeći prema opisu Martinucija, bila su izdvojena na ostrvu. Građevinu koju Sansovino pominje kao Stari Lazaret zapravo predstavlja karantin, koji je Senat odlučio da sagradi 1423. Na ovom mestu Sansovino potpuno preuzima podatke koje je u svoje vreme izneo Marin Sanudo. Ove redove Sansovino je napisao krajem 
XVI veka kao očevidac kuge, koja je opustošila Veneciju i njenu Terafermu 1576. Po njegovom opisu Stari Lazaret imao je priora s „dostojnom platom“, nekoliko medika mada ne navodi njihov tačan broj „E altre persone pronte per $i$ seruigi degli ammalati“. [19 p232] Tokom ove epidemije u ovom lazaretu pomoć je potražilo 8.000 zaraženih osoba. [19 p232]

Karantin koji je nastao preko puta Starog Lazareta 1468. do vreme kada je Sansovino zasnovao svoj rad već bio poznat među stanovnicima Venecije kao Novi (Lazaretto Nouovo). On je imao 100 prostorija za bolesnike i karantin u kome je osoba, koja je napustila Stari Lazaret, morala da provede u kontumaciji 22 dana. Sansovino koji je tokom kuge izgubio jedanaestogodišnju kćer i suprugu dobro je upoznao organizaciju institucija, gde su one jedno vreme potražile utočište. Čovek koji je na najgori način iskusio kugu zabeležio je da je tokom ove epidemije 8.000 do 10.000 ljudi prebačeno u lazarete na više od 3.000 barki. [19 p233] Priređivač Sansovine knjige don Martinuci primećuje sredinom XVII veka da se tokom epidemije 1630-1631 pokazao sav njihov nedostatak. Usled velikog broja obolelih nedostajali su medici, hirurzi i lica "opremljena odgovarajućim lekovima". [19 p233] Ovakvi komentari otkrivaju da je pojavom krize u Veneciji, među prvima stradala njena zdravstvena služba. U sklopu reforme 1628. odlučeno je da se za potrebe ovog Magistrata na godišnjem nivou iz blagajne izdvaja 4.000 dukata. [20 p220]

Sve do 1721. zdravstvena služba Venecije smatrana je bez premca u Evropi. Holandski konzul tražio je detaljne informacije u vezi sa njenom organizacijom i funkcionisanjem. [2] U ovo vreme zdravstvena služba ponovo je postala aktuelna usled strahovite epidemije kuge koja je pogodila Marsej. Ona je podstakla Ludovika Muratorija da napiše kraći traktat u kome je primarno mesto stekao opis obolelih od kuge. Njih Muratori, zasnivajući svoje delo na izveštajima medikusa prema očiglednim simptomima koje je bolest na njihovom telu izazvala, klasifikuje u četiri grupe, pri čemu razmatra svaku pojedinačno, predlažući lekove i medicinski tretman za svaku. [21] Zdravstvena služba u Veneciji tokom pomenutog veka razvijala se u skladu s napretkom u nauci, u prvom redu u medicini. Prvi registrovani esnaf medika u istoriji Venecije zabelžen je 1321, kada je i nastao njegov statut. Međutim, nakon osnivanja Magistrato alla Sanità rad i prijem članova u ovom esnafu postao je predmet nadzora ovog tela. Više puta je u istoriji Venecije posebnim zakonskim regulativama utvrđivan način bavljena medika lekarskom praksom, za šta je, pre svega, bio potreban doktorat odbranjen na jednom od tadašnjih univerziteta. U XVIII veka primećuje se veća sekularizacija obrazovanja, što je slučaj i sa najznačajnijim 
mletačkom obrazovnom istitucijom - Univerzitetom u Padovi. U pomenutom veku detaljno se uređuje medicinska praksa i uslovi pod kojima se lekari mogu baviti svojim profesijom, anticipirajući pojavu zakonodavstva o zdravstvu. [20 pp 208-226] U tom smeru kreću se i obaveze, kojima je Zdravstveni magistrat u ovom periodu bio opterećen.

\section{Reference:}

1. Testi poseduti dalla biblioteca Scienze della Storia e della documentazione storica la Peste del 1348. Università degli studi di Milano Bibioteca di Scienze dell Storia e della Documentazione Storica (Medioevo, Età Moderna, Età Contemporanea). http://www. sba.unimi.it/files/bstoria/peste.pdf, 1-6. (19.11.2011)

2. Cipolla CM. Public Health and the Medical Profession in the Renaissance. Cambridge: Cambridge University Press; 1976.

3. Sabellici MA. Historiae Rerum Venetarum Ab Urbe Condita Libri XXXIII. u: Degl' Istorici delle cose Veneziane I quali hanno scritto per Pubblico Decreto. tom. I-X. Venezia: Appreso il Lovisa; 1718.

4. Sandi V. Principi di Storia Civile della Repubblica di Venezia dalla sua fondazione sino all' anno di N. S. 1700. Della parte seconda che contiene i tempi sono al 1500. Volume secondo. Dall'anno 1450. sino al 1500. Venezia: Presso Sebastian Coleti; 1755.

5. Sanudo, MG. La vite dei Dogi, 1423-1474. vol. I-II. [pr. Frison C]. Venezia: La Malcontenta; 1999.

6. Chambers D, Fletcher J, Pullan B, ur. Venice. A Documentary History 1450-1630. Toronto: Renaissance Society of America, University of Toronto Press; 2001.

7. Sagredo A, ur. Annali Veneti dall' Anno 1457. al 1500. del Senatore Domenico Malipiero ordinati e abbreviati del Senatore Francesco Londo. u: Archivio Storico Italiano ossia Raccolta di opere e docmenti rieguardanti la Storia d'Italia tomo VII parte Primo. Firenze: Gio Pietro Vieusseux; 1843.

8. Preto P. Peste e società a Venezia nel 1576. Venezia: Neri Poza; 1978.

9. Moryson F. An Itinerary Containing his Ten Yeers Travell through the Twelve Dominions of Germany, Bohmer-Land, Sweitzerland, Netherland, Denmarke, Poland, Italy, Turkey, France, England, Scotland, \& Ireland. I-IV. 
Glazgow: Printed at University Press; 1907.

10. Panzac D. Quarantaines et lazarets: 1' Europe et la peste d'Orient (XVIIeXXe siècles). Aix-en-Provence: Edisud; 1986.

11. Vanzan-Marchini NE. Venezia e i lazzaretti mediterranei. Venezia: Edizioni della Laguna; 2004.

12. Cipolla CM. Cristofano and the Plague. A Study in the History of Public Health in The Age of Galileo. Berkeley-Los Angeles: University of California Press; 1973.

13. Cipolla CM. Fighting the Plague in Seventeenth Century Italy. Wisconsin: The University of Wisconsin Press; 1981.

14. Tadino A. Raguaglio dell' origine et Giornali sucessi della Gran Peste. Contagiosa, Venefica, \& Malefica seguita nella città di Milano, \& suo Ducato dall' Anno 1629. sino all' Anno 1632. Con le loro successive Provisioni, \& Ordini. In Milano: Per Filippo Ghisolfi; 1648.

15. Nani B. Historia della Republica di Veneta. vol. I-II. In Venetia: Per Combi, \& La Noù.; 1686.

16. Ripamonti G. La Peste di Milano del 1630. Libri cinqui. Cavati dagli Annali della Città e scritti per ordine dei LX Decurioni. Milano: Tipoigrafia e Libreria Perolla e E.; 1841.

17. Nani B. The History of the Affairs of Europe in this present Age, But more particularly of the Republick of Venice. London: Printed for J. M. for John Starkley; 1673.

18. Nani B. Historia della Republica Veneta, Degl' Istorici delle cose Veneziane, I quali hanno scritto per Pubblico Decreto. tom. VIII-IX. Venezia: Apresso in Lovisa; 1722.

19. Sansovino F. Venetia. Città Nobilissima, et singolare. Descritta in XIIII Libri. Con aggiunta di tutte le Cose Notabili della stessa Città, fatte \& occorse dall' Anno 1580. sino al presente 1663. da don G. Martinioni. Venetia: Apresso Steffano Curti; 1663.

20. Sandi V. Principi di storia civile della Repubblica di Venezia. Dall' anno di N.S. 1700. sino all' anno 1767. vol. I-III. Venezia: Presso Sebastian Coletti; 1769.

21. Muratori, LA. Dettaglio della Peste di Marsiglia Publicato da i Medici che hanno operato in essa, con alcune osservazioni. In Milano: Nella stamperia di Felice-Carlo Mosca; 1721. 


\section{Summary}

The development of medical services in Venice started in the mid $14^{\text {th }}$ century and it was predominantly influenced by the outbreak of the plague (Black Death), after which the first health care regulations were introduced. Several decades on, the organization of the health care service was finalized. Regulations passed by the Senate in the mid $15^{\text {th }}$ century were of major importance. Several decades later, a separate Magistrate (Magistrato alla Sanità) was set up to deal with public health care. This institution continued to operate in an almost unchanged form until the final fall of the Republic of Venice in 1797.

Rad predat: 12.2.2013.

Recenziran: 16. 3. 2013.

Prihvaćen: 25. 3. 2013. 